\title{
Osteopati Yaklaşımı; Bel ve Boyun Ağrılarında Yeri
}

\author{
Osteopathic Approaches to Lumbar and Cervical Ppain
}

\author{
Elif Kaya, Turgay Altınbilek \\ Serbest hekim, İstanbul \\ Yazışma Adresi / Correspondence: \\ Dr. Turgay Altınbilek \\ Fenerbahçe Mah. Ahmet Mithat Efendi Cad., No:6 D:4 Doğu Apt. Kalamış, 34726 Kadıköy/İstanbul \\ E-mail: turgayaltinbilek@hotmail.com \\ Orcid \\ Elif Kaya : https://orcid.org/0000-0002-0703-7047 \\ Turgay Altunbilek: https://orcid.org/0000-0002-0363-387X
}

Geliş Tarihi / Received : 07-04-2019 Kabul Tarihi / Accepted : 28-04-2019 Yayın Tarihi / Online Published: 30-09-2019

Kaya E., Altınbilek T., Osteopati Yaklaşımı; Bel ve Boyun Ağrılarında Yeri,

J Biotechnol and Strategic Health Res. 2019;3(Özel Sayı):86-90 DOI: bshr.550371

\footnotetext{
Özet

Bel ve boyun ağrıları oldukça yaygın görülen, kalıcı fonksiyonel kayıplara ve iş gücü kaybına neden olan en önemli bir sağılı sorunudur. Ağrı hastaların psikolojik durumlarını önemli oranda etkilemekte, beraberinde hastaların günlük yaşam aktivitelerinde kısıtlama ve depresyona yatkınlık oluşturmaktadır. Osteopatik manuel terapi (OMT); kas iskelet sistemi hastalıklarında konvansiyonel tedaviyi tamamlamak amacıyla sıkça kullanılan, önemli bir tedavi șeklidir. OMT bedeni bir bütün olarak değerlendiren, homeostatik mekanizmaları geliștiren, yapı ve fonksiyon ilișkilerini en üst düzeye çıkarmak için tanı ve tedavi stratejileri içeren bir yaklaşımdır. OMT, kasiskelet ağrısını azaltır, disfonksiyonun vücut sistemleri üzerindeki etkisini azaltır, solunum mekaniğini geliştirir, venöz ve lenfatik drenajı iyileştirir. OMT parietal, visseral ve kranial osteopati olmak üzere 3 sistem üzerinden etki gösterir. Parietal Osteopati; Kas iskelet sisteminden kaynaklanan ağrı ve disfonksiyonların tedavisinde kullanılır. Visseral osteopati, visseral yapılardaki problemleri tedavi ederek, bunların neden olduğu ağrı ve șikâyetleri ortadan kaldıran bir tedavi yaklaşımıdır. Kranial osteopati hassas ve hafif dokunuşlarla yapılan osteopatik bir tedavi tipidir. Hastada var olan ağrı ve șikâyetlerin ortadan kaldırılmasına yardımcı olur.

Anahtar Bel ağrıları, boyun ağrıları, osteopati

Kelimeler

Abstract

Lumbar and cervical pain are important health problems which frequently causes functional health and labour deficits. Pain causes physicologic effects and causes depression in the patients which limits daily life activites. Osteopathic manuel therapy (OMT) in an important treatment modality which is used to complement conventional musculo-skeletal diseases. OMT is an approach which evaluates the body as a whole, improves the homeostatic mechanisms with its structure and functional bindings to the highest level and includes diagnosis and treatment strategies. OMT alleviates musculo-skeletal pain, decreases dysfunctions in the body systems, improves inspiration mechanics and the venous and lymphatic drainage. OMT has effect on 3 sistems; parietal, visceral and cranial. Parietal osteopaty is used in pain and dysfunctions that are caused from musculo-skeletal systems. Visceral osteopathy is a treatment approach that is used to diminish pain which is caused by the visceral problems. Cranial osteopathy is a treatment approach using mild and sensitive touches to the cranial structures. It is used to eliminate pain and complaints of the body as a whole.

Keywords Low back pain, neck pain, osteopathy
} 


\section{Giriş}

Bel ağrıları, oldukça yaygın görülen, kalıcı fonksiyonel kayıplara ve iş gücü kaybına neden olan en önemli bir sağlık sorunudur. Toplumun \% 80'i hayatlarının herhangi bir döneminde en az bir defa bel ağrısı geçirmektedir ${ }^{1,2}$.

Bel ağrılarının en çok görülen nedeni mekanik bozukluklardır. Ani oluşan bir travmanın yanında, tekrarlayan travmaların da önemli rolü vardır. Ağır yaşam ve çalışma koşulları, kötü statik ve dinamik postür, yanlış vücut mekaniklerinin kullanımı, karın ve sırt kaslarının güç ve fleksibilitesinde ve kardiyovasküler enduransta azalma, sigara içme ve vibrasyon gibi risk faktörlerinin bel ağrısına sebep olduğu bilinmektedir ${ }^{3}$. Gastrointestinal ve böbrek hastalıkları ve disfonksiyonları da bel boyun ağrısına sebep olabilmektedir².

Omurgadaki kas iskelet sistemi şikâyetleri arasında bel ağrılarından sonra en sık görülen şikayet, boyun ağrılarıdır. ${ }^{4}$ Hastaların \%40-70'i de hayatları boyunca en az bir kez boyun ağrısı geçirirler. ${ }^{5}$

Çeşitli popülasyonlarda boyun ağrısı oldukça sık görülmektedir.. Boyun ağrısı hastanın yaşam kalitesini ve sağlık hizmeti ihtiyacını büyük ölçüde etkilemektedir. ${ }^{6}$

Kronik ağrı hastaların psikolojik durumlarını önemli oranda etkilemekte, beraberinde hastaların günlük yaşam aktivitelerinde kısıtlama ve depresyona yatkınlık oluşturmaktadır. Bel ve boyun ağrılı hastalar aynı zamanda direkt ve indirekt sağlık harcamaları açısından oldukça yüksek maliyette bir hastalık grubundadırlar ${ }^{1,4,7}$.

Osteopatik manuel terapi (OMT); kas iskelet sistemi hastalıklarında konvansiyonel tedaviyi tamamlamak amacıyla sıkça kullanılan, önemli bir tedavi şeklidir ${ }^{8-10}$. Osteoporoz dişında, her yaş grubunda ortaya çıkan, kas iskelet sistem hastalılarında kullanılmaktadır ${ }^{11}$.

OMT, 19. yüzyıldan beri, doktorların ve sağlık profes- yonellerinin ellerini ve osteopati alanındaki bilgilerini kullanarak uyguladığı bütüncül bir tedavi yöntemidir. Osteopatinin kurucusu Dr. Andrew Taylor Still; hastalık ve iyileşme sürecinin bütün bedeni ilgilendirdiğini, her lokal problemin tüm bedenin bütünlüğü içerisinde tedavi edilmesi ve belirgin bir iyileşme içinde hastalık sürecinin arkasındaki mekanik dengesizliğin bulunması ve tedavi edilmesinin önemini vurgulamıştır ${ }^{12,13}$.

1870’ li yıllarda Andrew Taylor Still, OMT’nin kan dolaş1mını iyileştirip, bedenin kendi kendini iyileşmesini sağladığını teorik olarak ispatlamıştır. ${ }^{14}$

OMT bedeni bir bütün olarak değerlendiren, homeostatik mekanizmaları geliştiren, yapı ve fonksiyon ilişkilerini en üst düzeye çıkarmak için tanı ve tedavi stratejileri içeren bir yaklaşımdır. OMT, kas-iskelet ağrısını azaltır, disfonksiyonun vücut sistemleri üzerindeki etkisini azaltır, solunum mekaniğini geliştirir, venöz ve lenfatik drenajı iyileştirir, homeostasisi destekler ve fonksiyonları en uygun hale getirir. ${ }^{13,15}$

OMT; sağlığı korumada ve hastalıklarla mücadele etmede geniş çaplı yaklaşımlar içermekte, tanı ve tedavide bazı temel prensiplere dayanmaktadır. Bunlar; Beden dinamik fonksiyonel bir ünitedir. Sağlık; beden, akıl ve ruhsal durumdan etkilenmektedir. İnsan bedeni kendi kendini düzenleyen mekanizmalara sahiptir ve doğal olarak kendi kendine iyileşmektedir. ${ }^{11}$

OMT dünya çapında batılı gelişmiş ülkeler tarafından uygulanmaktadır. OMT; ABD, Avusturalya, Yeni Zelanda ve Birleşik Krallıkta diğer konvansiyonel tedavilerle beraber tedavi amaçlı uygulanmaktadır. ${ }^{16}$

ABD'de osteopati hekimleri hem standart medikal tedavi hem de OMT konusunda eğitilmekte ve lisans verilmektedir. Geleneksel tıp ve tamamlayıcı/alternatif tıp arasındaki uçurumu birleştiren kabiliyetleri, osteopati hekimlerinin özellikle kronik bel ağrılı hastalarda başarılı olmalarını 
sağlamıştır. ${ }^{17}$

OMT parietal, visseral ve kranial osteopati olmak üzere 3 sistem üzerinden etki gösterir. ${ }^{12}$

Parietal Osteopati; Kas iskelet sisteminden kaynaklanan ağrı ve disfonksiyonların tedavisinde kullanılır. Kısıtlanmış veya kilitlenmiş eklemlerin fizyolojik hareket açıklığını düzelterek eklemlerin serbestleştirilmesine ve ağrının ortadan kaldırılmasına katkı sağlar. ${ }^{18,19}$ (Resim 1)

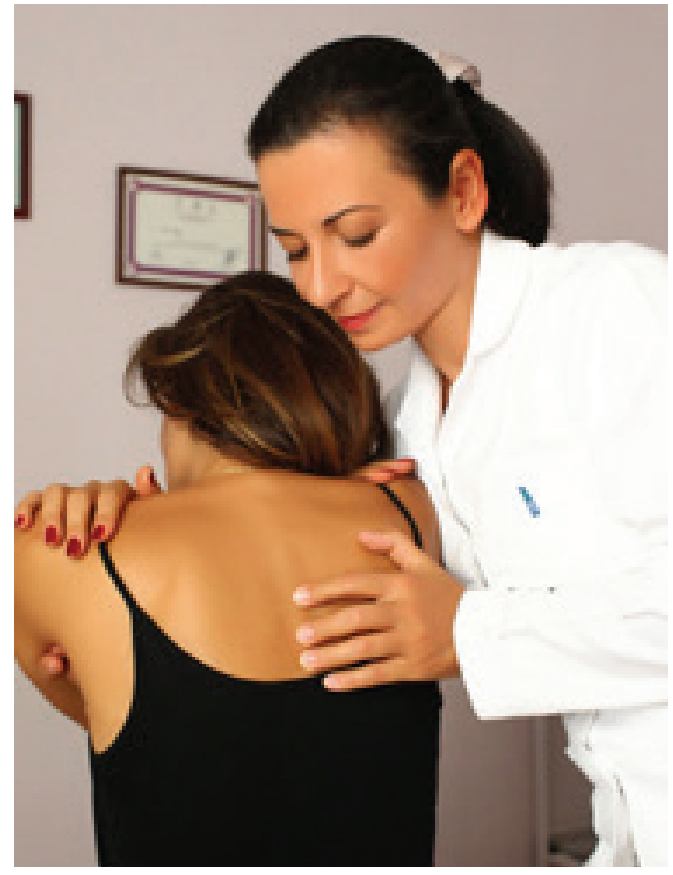

Resim 1 Parietal Osteopati

Visseral Osteopati; Visseral problemler omurga, eklemler ve vücudun diğer bölgelerinde ağrı ve problemlere neden olabilir. Sağ omuz ağrısı, safra kesesi veya karaciğerden, sol omuz ağrısı, mide, kalp veya dalaktan kaynaklanabilir. Bağırsaklardaki problemler eklemlerde ağrıya, prostat veya uterustaki problemler, bel, kalça ve diz ağrılarına sebep olabilir. Tüm bu sorunlar aynı anda boyun ağrısı da yapabilirler ${ }^{12,19,20}$.

Visseral osteopati, sindirim, solunum, dolaşım, üreme gibi visseral yapılardaki problemleri tedavi ederek, bunların neden olduğu ağrı ve şikayetleri ortadan kaldıran bir tedavi yaklaşımıdır. ${ }^{20,21}$ (Resim 2)

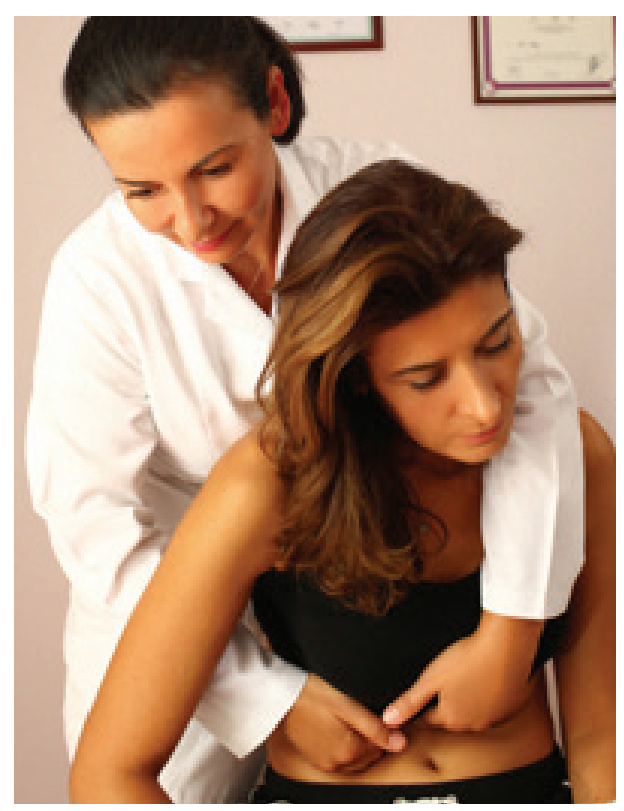

Kranial osteopati hassas ve hafif dokunuşlarla yapılan osteopatik bir tedavi tipidir. Germe ve gevşetme teknikleri ile stresin baş ve tüm vücutta yarattı̆̆g gerginliğin ortadan kaldırılmasını teşvik eder. Hastada var olan ağrı ve şikâyetlerin ortadan kaldırılmasına yardımcı olur. Hastaların sadece semptomlarını ortadan kaldırmakla kalmaz, tüm beden sağlığının da kazanılmasına yardımcı olur. ${ }^{22}$ (Resim 3)

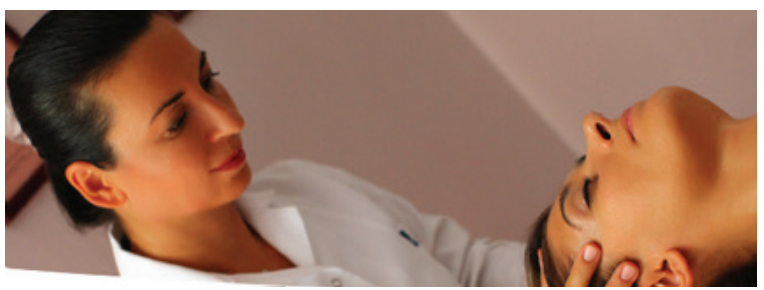

Resim 3 Kranial Osteopati

OMT, vücudun birçok doku ve bölgelerine uygulanabilir. Bazen uygulama bölgesi, semptomatik bölgeden uzakta, uygulayıcı hekimin klinik olarak bulduğu yer olabilir., ${ }^{10,23}$ OMT, yüksek hız, düşük amplitüdlü ve orta hız, orta amptitüdlü manuel teknikleri, spinal manipülasyon, yumuşak doku germe, yuvarlama ve basınç teknikleri, miyofasiyal 
germe ve gevşetme teknikleri, miyofasiyal ağrılı nokta tedavisi, pozisyonel tedavi, kas enerji teknikleri ve visseral teknikleri içermektedir. ${ }^{10}$

OMT teknikleri somatik disfonksiyonda kullanılır. Somatik disfonksiyon, somatik sistem ile ilgili unsurların fonsiyonlarının bozulması veya değişmesi; iskelet, eklem, miyofasiyal, vasküler, lenfatik ve nöral yapılardaki değişikliklerdir ${ }^{17,19,24}$.

OMT uygulayan doktorlar ve sağlık profesyonelleri hasta tedavisinde osteopati prensiplerini uygularken en son tıbbi ve bilimsel bilgileri bir araya getirirler. OMT uygulayıc1ları, her hastanın klinik bulgu ve semptomlarının birçok fiziksel ve fiziksel olmayan faktörlerin etkileşimi sonucu olduğunu anlamışlar ve iyileşme sürecinde bu faktörlerin dinamik olarak birbirleriyle ilişkisini ve beraberinde hasta Osteopat ilişkisinin öneminide vurgulamışlardır. Tedavi yaklaşımları da hastalık merkezli olmaktan çok hasta merkezlidir $^{25}$.

OMT 140 yıldan daha fazla bir süre uygulanmasına rağmen, etkinliğini tam olarak gösteren çok az sayıda sağlam çalışma vardır. ${ }^{26}$

Kronik bel ağrılı hastalarda medikal tedaviye ek olarak OMT’nin kısa vadede etkinliğini tayin etmek için osteopatik sağlık sonuçlarını gösteren bir çalışma yapılmıştır. $\mathrm{Bu}$ çalışmanın sonuçları, OMT’nin bel ağrılı hastalarda istatistiksel olarak anlamlı ve klinik olarak bariz iyileşme gösterdiğini ortaya koymuştur. ${ }^{17}$

Kronik bel ağrılı 230 hasta üzerinde yapılan randomize çift kör çalışmada, OMT teknikleri 15 osteopatik hekim ve yardımciları tarafından $0-1-2-4-6$ ve 8 . haftalarda 15 dakikalık tedavi seansları boyunca uygulanmış, 12 hafta sonu yapılan değerlendirmede orta dereceli ağrıda (VAS) azalma görülmüş ve OMT genelde etkili olarak değerlendirilmiştir. Lomber omurga, sakrum ve pelvisin biyomekanik disfonksiyonunun iyileşmesi için kısa dönem içinde yapılan OMT genelde etkili görülmüştür. ${ }^{23}$

Randomize çift kör plasebo kontrollü OMT ve terapötik ultrason tedavisinin nonspesifik kronik bel ağrılı hastalarda kısa vadeli iyileşme sonuçlarını göstermek için yapılan bir çalışmada, hastalar OMT, plasebo OMT, ultrason ve plasebo ultrason olarak 4 gruba ayrılmıs, her gruba 8 hafta boyunca 6 tedavi uygulanmıştır. 12 haftanın sonunda OMT ve plasebo OMT arasında, orta dereceli ve anlamlı iyileşmeler karşılaştırılmış; OMT lehine ağrıda azalma ve orta dereceli iyileşme \%30, ağrıda azalma ve anlamlı derecede iyileşme \%50 veya daha fazla olduğu görülmüştür. OMT’nin kronik bel ağrılı hastaların iyileşmesinde orta derecede etkili tedavi şekli olduğu görülmüştür. ${ }^{8}$

Postpartum bel ağrılı 80 kadın hasta (40 OMT, 40 kontrol) üzerinde yapılan çalışmada, ağrı ve yorgunluk değerlendirilmiştir. 12 hafta içinde, 2 hafta aralıklarla 4 defa OMT uygulanmış; tedavi sonrası OMT grubunda ağrı ve yorgunluğun azaldığı, daha sonra yapılan takiplerde de OMT grubunda iyileşmenin daha fazla olduğu görülmüş. ${ }^{27}$

Kronik nonspesifik bel ağrılı erişkinlerde OMT uygulayan hekimler tarafından manuel terapinin etkinliğini değerlendiren 2 çalışmanın birinde, osteopatik girişimin, plasebo müdahale etkisine benzer etkisi olduğu, diğer çalışmada ise egzersiz ve fizyoterapiye benzer etkisi olduğu gösterilmiştir. ${ }^{16}$

Yapılan çalışmaların derlemesinde, bel ağrılarının tedavisinde spinal manipülasyon için kanıtlar çelişkili bulunmuştur. Bazı çalışmalarda spinal manipülasyonun akut veya subakut bel ağrılarında ağrı ve fonksiyonel durum üzerine kısa dönem önemli etkilere sahip olduğu fakat diğer tedavilerle kıyaslandığında bu etkinin kliniğe tam yansımadığı belirtilmiştir. Birçok çalışmanın derlendiği bir araştırmada ise, spinal manipülasyonun kronik bel ağrısında ağrıyı azaltma ve fonksiyonel iyileşmede etkili olduğu sonucunu ortaya çıkarmıştır. ${ }^{28,29}$ 
Kronik non-spesifik boyun ağrısı hastalarında yapılan yapılan bir çalışmada, tüm katılımcılara ortalama 10 hafta boyunca haftada bir kez 12 dakikalık bir sham ultrason uygulanmış. ayrıca, her hafta 24 katılımcıya 45 dakikalık ,Osteopatik manipülatif terapi (OMT) uygulanmış. Tedavinin bitiminden sonra 12 hafta boyunca 40 katılımcı takip edilmiş. Ortalama ağrı şiddeti osteopatik grupta, kontrol grubuna göre anlamlı derecede düşmüş. Çalışmacılara göre OMT, kronik non-spesifik boyun ağrısı hastaları için umut verici bir tedavi rejimi olabilir sonucu ortaya çıkmış. ${ }^{30}$

Kronik boyun ağrısı olan 25 gönüllü hasta üzerinde, OMT ve egzersiz grubu olarak yapılan karşılaştırmalı çalışmada, OMT grubu VAS ve ROM artışı yönünden egzersiz grubuna göre daha etkili olduğu, fakat hiçbirinin de EMG değişikliğine yol açmadığı görülmüş. ${ }^{31}$

2 ila 12 hafta arasında devam eden boyun ve sırt ağrısı olan 201 hasta üzerinde aralıklarla yapıla 3 seans osteopatik spinal manipülasyon sonuçlarının, 2. ayda yapılan kontrollerinde etkili olduğu görülmüș. ${ }^{32}$

Osteopatik tedavinin boyun ağrısı olan kişilerde algılanan ağrı ve sakatlık düzeyini azaltıp azaltmayacağını araştıran bir çalışmada, boyun ağrısı (olan 17 hasta ( 7 erkek, 10 kadın) dahil edilmiş. Deneklere 4 haftalık osteopatik tedavi uygulanmış. Hastaların sakatlık düzeyleri ve ağrılarının anlamlı düzeyde azaldığı görülmüș. ${ }^{33}$

Manipülasyonun etkili olabilmesi, uygun hasta seçimi, uygulanan teknik ve uygulayan kişinin tecrübesine bağlı olduğu çok sayıda çalışmada vurgulanmıştır. ${ }^{29}$

$\mathrm{Bu}$ araştırma ve çalışmaların sonuçlarına göre, OMT; kas iskelet sistemi bozukluklarında konvansiyonel tedaviyi tamamlamak amacıyla osteopati hekimleri tarafından sıkça kullanılan, önemli bir tedavi formudur. OMT sağlığı korumada ve hastalıklarla mücadele etmede bütünsel yaklaşımlarda bulunmakta, hasta hekim ilişkisinin önemini vurgulamakta ve hastalık merkezli olmaktan çok hasta merkezli yaklaşımda bulunmaktadır. OMT’nin etkili olabilmesi, uygun hasta seçimi, uygulanan teknik ve uygulayan kişinin tecrübesine de bağlıdır. Bu konuda daha geniş ve kapsamlı çalışmalara ihtiyaç olduğu görüşündeyiz.

Ülkemizde 2017 yılından beri Sağlık Bakanlığı tarafından yayınlanan Geleneksel, Tamamlayıcı ve Alternatif Tip Uygulamaları Yönetmeliği’ne göre, Sağlık Bakanlığı onaylı Osteopati sertifika programları verilmektedir. ${ }^{34}$ 
Journal of BSHR 2019;3(Özel Say1):85-90

KAYA, ALTINBILEK. Osteopati

Kaynaklar

1. Ay S., Evcik D. Kronik Bel Ağrılı Hastalarda Depresyon ve Yașam Kalitesi Yeni Tip Dergisi. 2008; 25: 228-231.

2. Almeida DC, Kraychete DC. Low back pain - a diagnostic approach. Rev Dor. São Paulo. 2017; 18: 173-7.

3. Narin S, Bozan Ö, Cankurtaran F, Bakırhan S. Kronik bel ağrll hastalarda fizyoterapi programinin fonksiyonel kapasite ve yaşam kalitesi üzerine etkisi. DEU Tip Fakültesi Dergisi. 2008; 22: 137-43.

4. Takmaz SA. Kronik bel-boyun ağrll hastaya yaklașım ve değerlendirme yöntemleri. TOTBID Dergisi. 2017; 16: 81-88.

5. Akalın E. Kronik boyun ağrll hastada ayırıcı tanı. TOTBİD Dergisi. 2017; 16: 112-117.

6. Guez M, Hildingsson C, Nilsson M, Toolanen G. The prevalence of neck pain, Acta Orthopaedica Scandinavica. 2002; 73 (4): 455-459.

7. Ambrose KR., Golightly YM. Physical exercise as non-pharmacological treatment of chronic pain: Why and when. Best Pract Res Clin Rheumatol. 2015; 29 (1): 120-130.

8. Licciardone JC, Minotti DE, Gatchel RJ, Kearns CM, Singh KP. Osteopathic manual treatment and ultrasound therapy for chronic low back pain:a randomized controlled trial. Ann Fam Med. 2013; 11 (2): 122-9.

9. Cerritelli F, Cicchitti L, Martelli M, Barlafante G, Renzetti C, Pizzolorusso G et al. Osteopathic manipulative treatment and pain in preterms: study protocol for a randomised controlled trial. Trials. 2015; 16: 84 .

10. Franke H,Franke JD, Fryer G. Osteopathic manipulative treatment for nonspecific low back pain: a systematic review and meta-analysis. BMC Musculoskeletal Disorders 2014; 15: 286.

11. Licciardone JC, Kearns CM, Hodge LM, Minotti DE. Osteopathic manual treatment in patients with diabetes mellitus and comorbid chronic low back pain: subgroup results from the Osteopathic Trial. J Am Osteopath Assoc. 2013; 113: 6.

12. Chila G.A. Foundations of Osteopathic Medicine. Third Edition. 2003; 3-21.

13. Earley, B.E., Luce, H. An introduction to clinical research in osteopathic medicine. Prim Care. 2010; 37 (1): 49-64.

14. Parker J, Heinking KP, Kappler RE. Efficacy of osteopathic manipulative treatment for low back pain in euhydrated and hypohydrated conditions: a randomized crossover trial. JAOA 2012; 112 (5): 276-284.

15. Kuchera, M.L. Applying osteopathic principles to formulate treatment for patients with chronic pain. J Am Osteopath Assoc. 2007; 107: 28-38.

16. Orrock PJ, Myers SP. Osteopathic intervention in chronic non-specific low back pain: a systematic review. BMC Musculoskeletal Disorders 2013; 14: 129.

17. Licciardone JC, Aryal S. Clinical response and relapse in patients with chronic low back pain following osteopathic manual treatment: Results from the Osteopathic Trial. Manual Therapy. 2014; 1: 8 .

18. Gamber RG, Shores JH, RussoD P, Jimenez BAC, Rubbin BR. Osteopathic manipulative treatment in conjunction with medication relieves pain associated with fibromyalgia syndrome: Results of a randomized clinical pilot Project. JAOA. 2002; 102 (6): 321-325.
19. Majchrzycki M, Hoffmann M, Marszałek S. Selected Osteopathic Techniques in Low Back Pain Treatment. Dysfunctions of the Locomotor System. 2010; 7-17.

20. Peeters L, Lason G. Osteopathic Medicine. The Liver and the Gallbladder. The International Academy of Osteopathy. 2013; 65-92.

21. Attali TV, Bouchoucha M, Benamouzig R. Treatment of refractory irritable bowel syndrome with visceral osteopathy: Short-term and long-term results of a randomized trial. Journal of Digestive Diseases. 2013; 14: 654-61.

22. Shi X, Rehrer S, Prajapati P, Scott T, Stoll ST, Gamber R.G, Downey HF. Effect of Cranial Osteopathic Manipulative Medicine on Cerebral Tissue Oxygenation. JAOA. 2011; 111: 12.

23. Licciardone JC, Kearns CM, CrowWT. Changes in biomechanical dysfunction and low back pain reduction with osteopathic manual treatment: Results from the Osteopathic Trial. Manual Therapy 2014; 19: 324-330.

24. Fryer G. Somatic dysfunction: An osteopathic conundrum. International Journal of Osteopathic Medicine. 2016; 1-12.

25. World Health Organization. Benchmarks for Training in Osteopathy. 2010; 3-4.

26. Tempelhof, S. Osteopathic medicine. Orthopade. 2012; 41 (2): 106-12.

27. Schwerla F, Rother K, Rother D, Ruetz M, Resch KL. Osteopathic Manipulative Therapy in Women With Postpartum Low Back Pain and Disability: A Pragmatic Randomized Controlled Trial. J Am Osteopath Assoc. 2015; 115 (7): 416-25.

28. Oral A, Ketenci A. Radiküler Bel ağrlarının tedavisinde fiziksel tıp ve rehabilitasyon yaklaşımları: en uygun ve etkin tedavinin belirlenmesi amacıyla kanttların gözden geçirilmesi ve güncel öneriler. Türk Fiz Tip Rehab Derg 2013; 59: 57-68.

29. Yıldırım A. Kronik diskojenik bel ă̆rıları ve cerrahi dıșı tedavi yöntemleri: güncelleme. Dicle Tip Dergisi. 2016; 43 (1): 181-191.

30. Schwerla F, Bischoff., Nürnberger A, Genter P, Guillaume J. Resch K.Osteopathic Treatment of Patients with Chronic Non-Specific Neck Pain: A Randomised Controlled Trial of Efficacy. Complementary Medicine Research. 2008; 15 (3): 138-45.

31. Galindez-Ibarbengoetxea X, Setuain I, Ramírez-Velez R, Andersen LL, González-Izal M, Jauregi A, Izquierdo M. Immediate Effects of Osteopathic Treatment Versus Therapeutic Exercise on Patients With Chronic Cervical Pain. Altern Ther Health Med. 2018; 24 (3): 24-3.

32. Williams NH, Wilkinson C, Russell I, Edwards RT, Hibbs R, Linck P, Muntz R. Randomized osteopathic manipulation study (ROMANS) pragmatic trial for spinal pain in primary care. Fam Pract. 2003; 20(6): 662-9.

33. Fryer G, Alvizatos J, Lamaro J. The effect of osteopathic treatment on people with chronic and sub-chronic neck pain: A pilot study. International Journal of Osteopathic Medicine 2005; 8 (2): 41-48.

34. Sağhlk alanı sertifikalı eğitim standartları, Osteopati. 2016. 